\title{
Prognostic Significance of Systolic Blood Pressure Changes During Dobutamine- Atropine Stress Technetium-99m Sestamibi Perfusion Scintigraphy in Patients With Chest Pain and Known or Suspected Coronary Artery Disease
}

\author{
Marcel L. Geleijnse, MD, Abdou Elhendy, MD, PhD, Ron T. van Domburg, MSc, \\ Riccardo Rambaldi, MD, Ambroos E.M. Reijs, MSc, Jos R.T.C. Roelandt, MD, PhD, \\ and Paolo M. Fioretti, MD, PhD
}

To investigate the prognostic value of dobutamine stressinduced changes in systolic blood pressure (BP) 418 patients (mean age 60 years, 238 men) with chest pain and known or suspected coronary artery disease, who underwent a dobutamine-atropine stress technetium$99 \mathrm{~m}$ sestamibi myocardial perfusion scintigraphic study, were followed up for $25 \pm 15$ months. Blood pressure was measured by automatic sphygmomanometry every 3 minutes. A marked decrease and increase in systolic BP from rest to peak were defined as changes of $\geq 20$ $\mathrm{mm} \mathrm{Hg}$, and $\geq 30 \mathrm{~mm} \mathrm{Hg}$, respectively. Worst outcome events were cardiac death ( $n=30$ ), nonfatal myocardial infarction ( $n=17$ ), and hospitalization for congestive heart failure ( $n=8$ ). A decrease in systolic BP (prevalence $16 \%$ ) was associated with older age and higher baseline systolic BP. Fixed and reversible sestamibi perfusion defects and follow-up results were similar to pa-

D obutamine stress technetium-99m sestamibi myocardial perfusion scintigraphy is a pharmacologic stress modality with diagnostic ${ }^{1-5}$ and prognostic ${ }^{6}$ properties comparable to dobutamine stress echocardiography. Previous dobutamine stress echocardiographic studies have reported that dobutamine stress-induced hypotension is - unlike exercise-induced hypotension ${ }^{7-10}$ not related to new or worsening wall motion abnormalities ${ }^{11-14}$ and the presence or extent of coronary artery disease. ${ }^{11,12}$ Furthermore, a relatively small echocardiographic study ${ }^{12}$ has supported these results with prognostic data that were similar for the hypotensive and the nonhypotensive group. To date, however, these findings were not confirmed by myocardial perfusion scintigraphic data. Also, it is not known whether a substantial increase in systolic blood pressure (BP)

\footnotetext{
From the Thoraxcentre and the Department of Nuclear Medicine, Uni versity Hospital, Rotterdam-Dijkzigt and Erasmus University, Rotter dam, The Netherlands. This study was supported in part by funds from the Dutch Heart Foundation (Grant NHS 94.135), The Hague, The Netherlands, and Cairo University Hospital, Cairo, Egypt. Manuscript received July 16, 1996; revised manuscript received and accepted December 12, 1996.

Address for reprints: Marcel L. Geleiinse, MD, Thoraxcentre, Ba 302, Dr Molewaterplein 40, 3015 GD Rotterdam, The Netherlands.
}

tients without a systolic BP decrease. In contrast, an increase in systolic BP (prevalence $24 \%$ ) was associated with younger age, lower baseline systolic BP, and with absence of a history of prior congestive heart failure or treatment with angiotensin-converting enzyme inhibitors. Furthermore, these patients had fewer fixed perfusion defects and tended to have fewer annual event rates $(3.5 \%$ vs $7.5 \%, p<0.10)$. In a multivariate model, an increase in systolic BP was not an independent predictor for subsequent events. In conclusion, a dobutamine-induced decrease in systolic BP is not associated with fixed or reversible sestamibi defects or adverse prognosis. An increase in systolic BP, however, is associated with less fixed sestamibi defects and a tendency toward less annual event rates. (C) 1997 by Excerpta Medica, Inc.

(Am J Cardiol 1997;79:1031-1035)

reflects, as in exercise studies, ${ }^{15,16}$ less myocardial damage and better prognosis.

\section{METHODS}

Patient selection: Over a 4-year period, between November 1990 and October 1994, 418 consecutive patients with chest pain were referred to the nuclear cardiology laboratory at the Thoraxcentre for the evaluation of suspected myocardial ischemia with dobutamine-atropine technetium-99m sestamibi single-photon emission computed tomographic imaging. All patients were unable to perform an adequate exercise test and none had prior heart transplantation, significant congenital or valvular heart disease, unstable angina, or known primary dilated cardiomyopathy. Mean age of the patients was $60 \pm 12$ years (range 23 to 85); 238 were men (57\%), 203 patients (49\%) had a previous myocardial infarction, and 55 patients $(13 \%)$ had coronary artery disease without known myocardial infarction. One hundred four patients $(25 \%)$ had typical angina, 205 (49\%) had atypical angina, and $109(26 \%)$ had nonanginal chest pain. At the time of the study 301 patients $(72 \%)$ were receiving antianginal therapy including $\beta$ blockers in $180(43 \%)$. 


\begin{tabular}{|c|c|c|c|c|c|c|}
\hline & $\begin{array}{c}\text { BP Fall } \geq 20 \mathrm{~mm} \mathrm{Hg} \\
(\mathrm{n}=65)\end{array}$ & $\begin{array}{c}\text { Others } \\
(n=353)\end{array}$ & $\mathrm{p}$ Value & $\begin{aligned} \text { BP Rise } & \geq 30 \mathrm{~mm} \mathrm{Hg} \\
(\mathrm{n} & =101)\end{aligned}$ & $\begin{array}{c}\text { Others } \\
(n=317)\end{array}$ & $\mathrm{p}$ Value \\
\hline Age $($ mean $\pm S D)$ & $65 \pm 10$ & $59 \pm 12$ & 0.0002 & $54 \pm 12$ & $62 \pm 11$ & 0.0000 \\
\hline Men & $38(59)$ & $200(57)$ & 0.7872 & $63(62)$ & $175(55)$ & 0.2050 \\
\hline Prior MI (history) & $28(43)$ & $177(50)$ & 0.2951 & 49 (49) & 156 (49) & 0.9029 \\
\hline CHF (history) & $13(20)$ & $69(20)$ & 0.9326 & (11) & 71 (22) & 0.0112 \\
\hline Angina (history) & $14(22)$ & $90(26)$ & 0.4977 & $25(25)$ & $79(25)$ & 0.9721 \\
\hline Hypertension (history) & $32(49)$ & 147 (42) & 0.2559 & $42(42)$ & $137(43)$ & 0.7726 \\
\hline$\beta$ blockers & $28(43)$ & $152(43)$ & 0.9935 & $42(42)$ & $138(44)$ & 0.7305 \\
\hline ACE inhibitors & 12 (19) & $85(24)$ & 0.3242 & 15 (15) & $82(26)$ & 0.0224 \\
\hline Diuretics & $16(25)$ & $70(20)$ & 0.3805 & $16(16)$ & $70(22)$ & 0.1767 \\
\hline
\end{tabular}

Dobutamine stress test: Infusion rate was $10 \mu \mathrm{g} / \mathrm{kg} /$ min for 3 minutes, increasing by $10 \mu \mathrm{g} / \mathrm{kg} / \mathrm{min}$ every 3 minutes up to a maximum of $40 \mu \mathrm{g} / \mathrm{kg} / \mathrm{min}$. In patients not achieving $85 \%$ of the predicted maximal heart rate and without symptoms or signs of myocardial ischemia, atropine was administered in addition to the maximal dose of dobutamine, starting with $0.25 \mathrm{mg}$ adminstered intravenously and repeated up to a maximum of $1.0 \mathrm{mg}$ within 4 minutes with continuation of dobutamine infusion. Throughout dobutamine infusion the electrocardiogram was continuously monitored (3 leads) and recorded (12 leads) at 1-minute intervals. Blood pressure was measured and recorded by automatic sphygmomanometry in the supine position at rest and at the end of each dobutamine (or atropine) stage. A hypotensive response was defined as a decrease in systolic BP from rest to peak of $\geq 20 \mathrm{~mm} \mathrm{Hg}$, in accordance with most previous studies. ${ }^{12-14} \mathrm{An}$ increase in systolic BP was defined as an increase of $\geq 30 \mathrm{~mm} \mathrm{Hg}$ from rest to peak, also in accordance with previous (exercise) studies. ${ }^{15,16}$ Reasons for interruption of the test were: horizontal or downsloping ST-segment depression $>0.2 \mathrm{mV}$ at an interval of $80 \mathrm{~ms}$ after the J point compared with baseline, ST-segment elevation $>0.1 \mathrm{mV}$ in patients without previous myocardial infarction, severe angina, a symptomatic reduction in systolic BP $>40 \mathrm{~mm} \mathrm{Hg}$, hypertension (BP $>240 / 120 \mathrm{~mm} \mathrm{Hg}$ ), and significant tachyarrhythmias.

Perfusion imaging: At peak stress, $370 \mathrm{MBq}$ of technetium-99m sestamibi was injected intravenously, while dobutamine infusion was continued for at least 1 minute. Stress scintigraphic images were acquired on average 1 hour after the termination of the dobutamine infusion. For resting studies, patients were reinjected with $370 \mathrm{MBq}$ of technetium-99m sestamibi $\geq 24$ hours after the stress study. Image acquisition was performed with a Gammasonics single-head Orbiter Camera (Siemens, Des Plaines, Illinois). As described previously, ${ }^{6}$ the tomographic views were grouped into 6 major segments: anterior, septum anterior, septum posterior, inferoposterior, lateral, and apical. Myocardial radiotracer uptake was evaluated visually (with the assistance of circumferential profiles analysis, including the normal values) for each of the 6 major segments both during rest and stress with a 4-point scoring method $(0=$ normal, 1 = equivocal or minimally reduced uptake, $2=$ moderately reduced uptake, and $3=$ severely reduced or absent uptake).

Coronary angiography: Coronary angiography was performed within 6 months in 164 patients (39\%). Significant coronary artery disease was defined as a diameter stenosis $\geq 50 \%$ in a major epicardial artery at quantitative coronary angiography. ${ }^{17}$

Follow-up: Follow-up data were obtained over a $25 \pm 15$-month period (range 6 to 54 months) by outpatient clinic assessment, review of case notes and contacting the patient, general practitioner or other hospitals when necessary. Outcome events were death (defined as cardiac death), nonfatal myocardial infarction, and hospitalization for congestive heart failure. Follow-up was complete in 413 patients $(99 \%)$.

Statistical analysis: Values were expressed as value $\pm \mathrm{SD}$, when appropriate. Comparisons (2-tailed) of patients with and without significant changes in systolic BP were performed with the Student's $t$ test for continuous variables and chi-square test for discrete variables. Differences in the $\mathrm{p}$ value $<0.05$ were considered significant. Differences of $<0.10$ were described as a tendency toward significance. Multivariate logistic regression using the BMDP package $^{18}$ was performed to identify factors that were related to events. A forward and backward stepping algorithm was used with a $\mathrm{p}$ value of $<0.05$ to identify independent predictors for events.

\section{RESULTS}

Dobutamine-induced decrease in systolic blood pressure: A decrease in systolic $\mathrm{BP} \geq 20 \mathrm{~mm} \mathrm{Hg}$ was present in 65 patients (16\%), and was associated with older age $(\mathrm{p}<0.001)$ and higher baseline systolic BP $(\mathrm{p}<0.0001)$. Severe, symptomatic hypotension as a test end point was present in only 4 patients (1\%). Gender, history of prior myocardial infarction or congestive heart failure, and the use of $\beta$ blockers, angiotensin-converting enzyme inhibitors or diuretics were not associated with a hypotensive systolic BP response (Tables I and II). There were no significant differences between patients with and without 
TABLE II Hemodynamic, Sestamibi Scintigraphic, and Angiographic Data

\begin{tabular}{|c|c|c|c|c|c|c|}
\hline & $\begin{array}{c}\text { BP Fall } \geq 20 \mathrm{~mm} \mathrm{Hg} \\
\quad(n=65)\end{array}$ & $\begin{array}{c}\text { Others } \\
(n=353)\end{array}$ & $p$ Value & $\begin{aligned} \text { BP Rise } & \geq 30 \mathrm{~mm} \mathrm{Hg} \\
(\mathrm{n} & =101)\end{aligned}$ & $\begin{array}{c}\text { Others } \\
(n=317)\end{array}$ & $\mathrm{p}$ Value \\
\hline \multicolumn{7}{|l|}{ Heart rate } \\
\hline Rest & $71 \pm 17$ & $69 \pm 13$ & 0.2647 & $68 \pm 11$ & $70 \pm 14$ & 0.1930 \\
\hline Peak & $132 \pm 17$ & $135 \pm 17$ & 0.2612 & $137 \pm 16$ & $134 \pm 17$ & 0.0841 \\
\hline Increase & $61 \pm 19$ & $66 \pm 18$ & 0.0547 & $69 \pm 17$ & $64 \pm 18$ & 0.0082 \\
\hline \multicolumn{7}{|l|}{ Systolic blood pressure } \\
\hline Rest & $151 \pm 23$ & $136 \pm 22$ & 0.0000 & $133 \pm 21$ & $140 \pm 24$ & 0.0040 \\
\hline Peak & $119 \pm 25$ & $154 \pm 29$ & 0.0000 & $177 \pm 28$ & $139 \pm 26$ & 0.0000 \\
\hline Increase & $-33 \pm 14$ & $18 \pm 22$ & 0.0000 & $45 \pm 18$ & $-1 \pm 20$ & 0.0000 \\
\hline Dobutamine dose & $38 \pm 6$ & $38 \pm 4$ & 0.6519 & $38 \pm 4$ & $38 \pm 5$ & 0.6305 \\
\hline Atropine dose & $0.58 \pm 0.30$ & $0.58 \pm 0.28$ & 0.9637 & $0.63 \pm 0.28$ & $0.56 \pm 0.28$ & 0.1557 \\
\hline \multicolumn{7}{|l|}{ Sestamibi scan } \\
\hline Fixed defect score & $2.4 \pm 2.6$ & $2.6 \pm 3.2$ & 0.6263 & $1.9 \pm 2.5$ & $2.8 \pm 3.2$ & 0.0227 \\
\hline Reversible defect score & $1.8 \pm 2.4$ & $1.6 \pm 2.0$ & 0.4550 & $1.4 \pm 1.8$ & $1.7 \pm 2.2$ & 0.2184 \\
\hline Total defect score & $4.2 \pm 3.8$ & $4.2 \pm 3.8$ & 0.9881 & $3.3 \pm 3.3$ & $4.4 \pm 4.0$ & 0.0127 \\
\hline \multicolumn{7}{|l|}{ Coronary angiography } \\
\hline Total number & $22(34)$ & $142(40)$ & 0.3330 & $38(38)$ & $126(40)$ & 0.7034 \\
\hline Normal arteries & $6(27)$ & $34(24)$ & 0.7351 & $9(24)$ & $31(25)$ & 0.9079 \\
\hline Diseased arteries & 16 (73) & $108(76)$ & 0.7351 & $29(76)$ & 95 (75) & 0.9079 \\
\hline Single-vessel disease & $6(27)$ & 56 (39) & 0.2736 & $15(40)$ & 47 (37) & 0.8088 \\
\hline Multivessel disease & $10(46)$ & $52(37)$ & 0.4265 & $14(37)$ & 48 (38) & 0.8889 \\
\hline
\end{tabular}

TABLE III Clinical End Points at Follow-Up

\begin{tabular}{|c|c|c|c|c|c|c|}
\hline & $\begin{array}{c}\text { BP Fall } \geq 20 \mathrm{~mm} \mathrm{Hg} \\
(\mathrm{n}=65)\end{array}$ & $\begin{array}{c}\text { Others } \\
(\mathrm{n}=353)\end{array}$ & $\mathrm{p}$ Value & $\begin{aligned} \text { BP Rise } & \geq 30 \mathrm{~mm} \mathrm{Hg} \\
(\mathrm{n} & =101)\end{aligned}$ & $\begin{array}{c}\text { Others } \\
(n=317)\end{array}$ & $\mathrm{p}$ Value \\
\hline $\begin{array}{l}\text { Follow-up (mean } \pm \text { SD) } \\
\text { Cardiac events }\end{array}$ & $23 \pm 14$ & $25 \pm 15$ & 0.2024 & $31 \pm 15$ & $23 \pm 14$ & 0.0000 \\
\hline Death & $5(8)$ & 25 (7) & 0.8610 & $5(5)$ & $25(8)$ & 0.3195 \\
\hline Death/Ml & $8(12)$ & $39\left(\begin{array}{ll}1 & 1\end{array}\right)$ & 0.7677 & $7(7)$ & 40 (13) & 0.1151 \\
\hline Death/Ml/CHF & $9(14)$ & $46(13)$ & 0.8582 & $9(9)$ & $46(15)$ & 0.1471 \\
\hline
\end{tabular}

systolic BP decrease with respect to dobutamine and atropine doses, fixed, reversible, and total sestamibi perfusion defect scores, presence and extent of coronary disease, and events during follow-up (Tables II and III).

Dobutamine-induced increase in systolic blood pressure: $\mathrm{An}$ increase in systolic $\mathrm{BP} \geq 30 \mathrm{~mm} \mathrm{Hg}$ was present in 101 patients $(24 \%)$ and was associated with younger age $(\mathrm{p}<0.0001)$, lower baseline systolic BP $(\mathrm{p}<0.005)$, absence of history of congestive heart failure $(\mathrm{p}<0.02)$, absence of the use of angiotensin-converting enzyme inhibitors $(\mathrm{p}<0.03)$, and a higher increase in heart rate $(\mathrm{p}<0.01)$ (Tables I and II). Patients with this systolic BP response had lower fixed $(p<0.03)$ and total $(p<0.02)$ sestamibi perfusion defect scores. However, the reversible defect score as well as the presence and extent of coronary disease were similar for both groups. Cardiac events during follow-up tended to occur less in patients with an increase in systolic BP, especially when the longer mean follow-up period was taken into consideration (Table III). Figure 1 shows that the annual death rates were $2.0 \%$ in patients with versus $4.0 \%$ in patients without an increase in systolic BP $(\mathrm{p}=\mathrm{NS})$; the annual death or nonfatal myo- cardial infarction rates were $2.7 \%$ versus $6.5 \%$ (p $<0.10$ ), respectively, and all event rates (death, nonfatal myocardial infarction, hospitalization for heart failure) were $3.5 \%$ versus $7.5 \%(\mathrm{p}<0.10)$, respectively. In a multivariable stepwise logistic regression model (including the patient characteristics listed in Table I, an increase in systolic BP, and fixed and reversible perfusion defects), only age, gender, history of congestive heart failure, and the presence of reversible defects were independent predictors of clinical outcome (Table IV). An increase in systolic BP was not an independent predictor.

\section{DISCUSSION}

Generally, dobutamine stress causes an increase in heart rate, a reduction in systemic vascular resistance, a reduction in stroke volume (after an initial increase), and an increase in cardiac output. ${ }^{12,19,20}$ Previous dobutamine stress studies have shown that as a net result, in general, there is a mild but significant increase in systolic BP. ${ }^{6,21}$ This would suggest that, on average, an increase in cardiac output corrects for the decrease in systemic vascular resistance. Although the pathophysiology of hypotension during dobutamine infusion has not been completely de- 


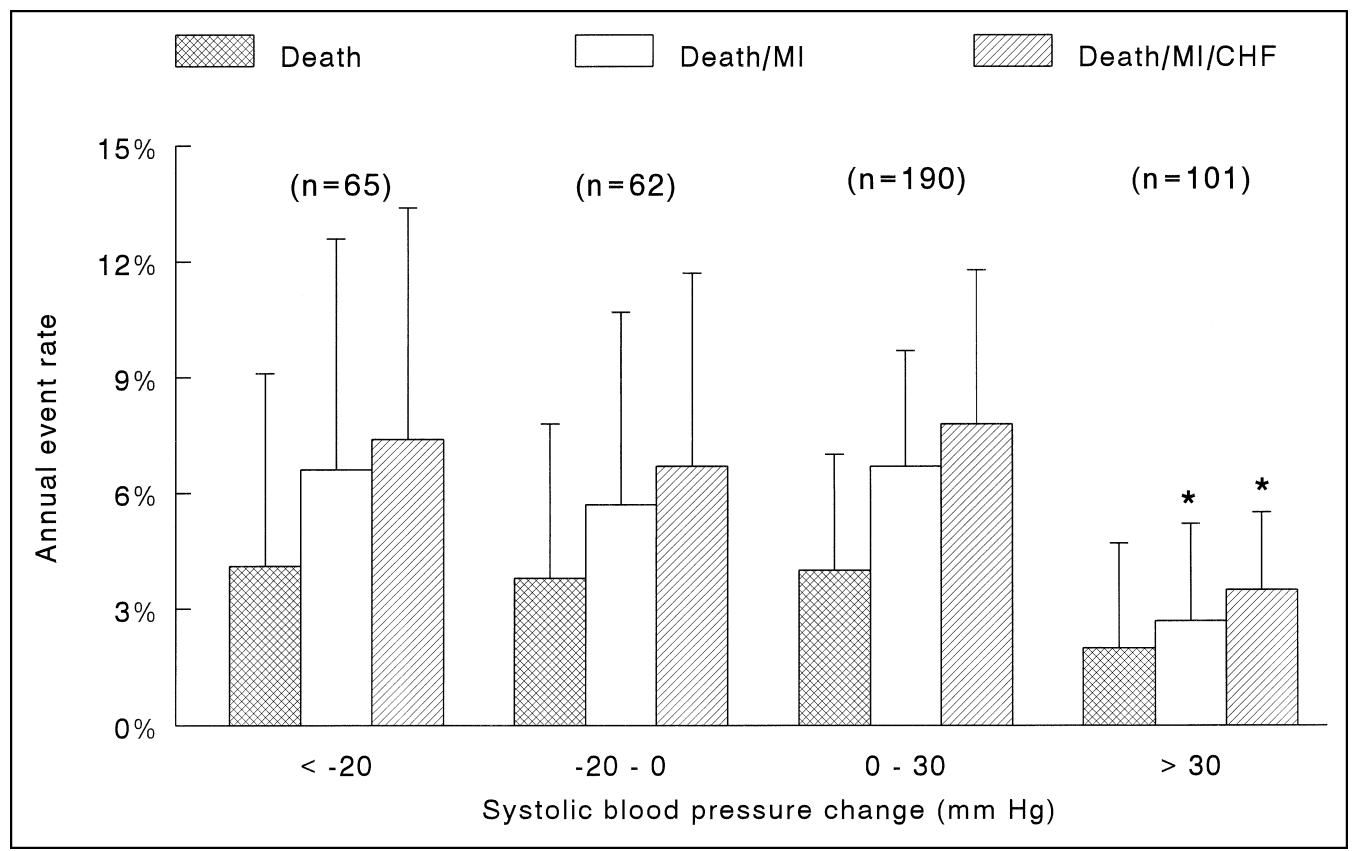

FIGURE 1. Annual event rates for the different systolic blood pressure responses. $\mathrm{CHF}=$ congestive heart failure; $\mathrm{MI}=\mathrm{myocardial}$ infarction; *The 101 patients with an increase in systolic BP $\geq 30 \mathrm{~mm} \mathrm{Hg}$ tended to have less events $(p<0.10)$ than the combined 317 patients without such a blood pressure response.

TABLE IV Independent Predictors of Cardiac Events (odds ratios, 95\% Cl)

\begin{tabular}{|lccc|}
\hline & Death & Death/MI & Death/MI/CHF \\
\hline Age $>65$ years & NS & $2.3(1.1-4.8)$ & $2.1(1.0-4.3)$ \\
Male gender & $2.4(1.0-6.1)$ & $2.3(1.1-4.8)$ & $2.6(1.3-5.3)$ \\
CHF (history) & $3.5(1.6-7.8)$ & $2.8(1.4-5.5)$ & $4.5(2.4-8.4)$ \\
Reversible defects & $2.1(1.0-4.6)$ & $3.0(1.6-5.9)$ & $1.9(1.0-3.5)$ \\
\hline
\end{tabular}

Variables included in the model were the patient characteristics of Table I, an increase in systolic BP, and fixed and reversible perfusion defects. Variables that were not significant for any end point are not displayed.

$\mathrm{Cl}=$ confidence interval; other abbreviations as in Table I.

fined, theoretically, it may result from (1) an inadequate increase in cardiac output to compensate for an expected decrease in systemic vascular resistance, and/or (2) a disproportionate decrease in systemic vascular resistance. An inadequate increase in cardiac output may be due to inadequate contractile reserve, severe ischemic left ventricular dysfunction, or left-sided obstructive heart disease. Dynamic left ventricular cavity obliteration due to strong inotropic stimulation was proposed as an important cause for reduced cardiac output and hypotension, ${ }^{22}$ especially in patients with dehydration, but later studies could not confirm this mechanism, ${ }^{14}$ and the proposed bolus of saline before dobutamine ${ }^{22,23}$ did not prevent cavity obliteration in a canine model. ${ }^{24}$ The second mechanism, a disproportionate decrease in systemic vascular resistance may be due to excessive sensitivity of the peripheral circulation to $\beta_{2}$-receptor stimulation, increased $\beta_{2}$-receptor density (deconditioned patients), or to a neurally mediated mechanism in which vigorous myocardial contraction stimulates the intramyocardial mechanoreceptors, resulting in sympathetic withdrawal and enhanced parasympathetic activity (the Bezold-Jarisch reflex). ${ }^{25}$ Based on the described mechanisms, mandatory for a marked increase in systolic BP are (1) absence of dramatic decrease in systemic vascular resistance, and (2) an increase in cardiac output by increase in heart rate and/or contractility.

The $16 \%$ prevalence of a hypotensive response in this study is in agreement with that reported in previous dobutamine stress echocardiographic studies with comparable hypotension definitions. ${ }^{12-14}$ In agreement with these previous reports, hypotension was associated with older age and higher baseline systolic BP. The consistent absence of histories of prior myocardial infarction or congestive heart failure, ischemia (whether assessed by stress echocardiography or perfusion imaging) or coronary artery disease, and worse prognosis in this and other studies $^{11-14,22,23,26}$ is strong indirect evidence of a dobutamine-induced hypotension mechanism that is primarily based on an excessive decrease in systemic vascular resistance, instead of a mechanism principally involving inadequate cardiac output. Because of the associations with older age and higher baseline systolic BP, a diminished baroreceptor reflex could play an additional role. ${ }^{27}$ Some investigators proposed that $\beta$ blockers offered some protection against hypotension by blocking peripheral vasodilatory $\beta_{2}$-receptors or diminishing vigorous contraction, resulting in less intramyocardial mechanoreceptor stimulation and dynamic obstruction. ${ }^{12}$ However, as in most previously reported studies, ${ }^{11,14} \beta$ blockers were not associated with a hypotensive response in the present study. Atropine can, by its vagolytic effects, increase systemic vascular resistance and pre- 
vent the development of a vasovagal reflex. However, the addition and dose of atropine was similar in both patient groups.

As mentioned before, a substantial increase in systolic BP generally requires an adequate increase in cardiac output. Patients without an increase in systolic BP were older, had lower increase in heart rate (as a consequence of their lower target heart rate), and had more fixed sestamibi perfusion defects, indicating damaged myocardium, with probably less contractile reserve. Additional evidence for a mechanism involving inadequate contractile reserve is the higher prevalence of histories of congestive heart failure in these patients. Hogue et al, ${ }^{28}$ although not dealing with this issue, reported that none of the 13 patients with a systolic BP increase $\geq 20 \mathrm{~mm} \mathrm{Hg}$ had histories of congestive heart failure, compared with 5 of 23 patients without such a systolic BP response. Patients with a marked increase in systolic BP in the present study had a 50\% reduction in annual cardiac events. We believe that this is further support for a better contractile reserve in these patients, because the extent and severity of fixed sestamibi perfusion defects are known to be related to prognosis. ${ }^{6}$ The more significant results in prediction of survival by systolic BP response in exercise studies ${ }^{15,16}$ can be a result of different (postmyocardial infarction) patient populations and the presence of the Bezold-Jarisch reflex, which will be more prevalent in patients stressed with a strong inotropic agent such as dobutamine, and in patients with preserved left ventricular rest function and contractile reserve. Indeed, this reflex will flaw the expected increase in systolic BP in more "normal" patients. Angiotensin-converting enzyme inhibitors were used more often in patients without a substantial increase in systolic BP. Apart from the accentuation of the vasodilatory effects of dobutamine, the more frequent use of these medications probably reflect the higher incidence of histories of congestive heart failure in these patients.

Clinical implications: It seems likely that a dobutamine stress-induced decrease in systemic vascular resistance plays a major role in the development of hypotension. Patients with hypotension during dobutamine stress are therefore not at higher risk for future events. Patients with a marked increase in systolic BP, however, are probably those with good contractile reserve (and without a marked decrease in systemic vascular resistance) and potentially better clinical outcome.

1. Günalp B, Dokumaci B, Uyan C, Vardareli E, Isik E, Bayhan H, Özgüven M, Öztürk E. Value of dobutamine technetium-99m-sestamibi SPECT and echocardiography in the detection of coronary artery disease compared with coronary angiography. J Nucl Med 1993;34:889-894.

2. Marwick T, D'Hondt A, Baudhuin T, Willemart B, Wijns W, Detry JM, Melin J. Optimal use of dobutamine stress for the detection and evaluation of coronary artery disease: combination with echocardiography or scintigraphy, or both? J Am Coll Cardiol 1993;22:159-167.

3. Herman SD, Labresh KA, Santos-Ocampo CD, Garber CE, Barbour MM Messinger DE, Cloutier DJ, Ahlberg AW, Heller GV. Comparison of dobutamine and exercise using technetium-99m sestamibi imaging for the evaluation of coronary artery disease. Am J Cardiol 1994;73:164-169.
4. Senior R, Sridhara BS, Anagnostou E, Handler C, Raftery EB, Lahiri A. Synergistic value of simultaneous stress dobutamine sestamibi single-photon emission computerized tomography and echocardiography in the detection of coronary artery disease. Am Heart J 1994;128:713-718.

5. Voth E, Baer FM, Theissen P, Schneider CA, Sechtem U, Schicha H. Dobutamine $99 \mathrm{~m}$-Tc-MIBI single-photon emission tomography: non-exercise-dependent detection of haemodynamically significant coronary artery stenoses. Eur J Nucl Med 1994;21:537-544.

6. Geleijnse ML, Elhendy A, van Domburg RT, Cornel JH, Reijs AEM, Roelandt JRTC, Krenning EP, Fioretti PM. Prognostic value of dobutamine-atropine stress technetium-99m sestamibi perfusion scintigraphy in patients with chest pain. J Am Coll Cardiol 1996;28:447-454.

7. Hammermeister KE, DeRouen TA, Dodge HT, Zia M. Prognostic and predictive value of exertional hypotension in suspected coronary heart disease. Am J Cardiol 1983;51:1261-1266.

8. Sanmarco ME, Pontius S, Selvester RH. Abnormal blood pressure response and marked ischemic ST-segment depression as predictors of severe coronary artery disease. Circulation 1980;61:572-578.

9. Weiner DA, McCabe CH, Ryan TJ. Prognostic assessment of patients with coronary artery disease by exercise testing. Am Heart J 1983;105:749-755.

10. Dubach P, Froelicher VF, Klein J, Oakes D, Grover-Mckay M, Friis R. Exercise-induced hypotension in a male population. Criteria, causes and prognosis. Circulation 1988;78:1380-1387.

11. Lieberman EB, Heinle SK, Wildermann N, Waugh RA, Kisslo JA, Bashore TM. Does hypotension during dobutamine stress echocardiography correlate with anatomic or functional cardiac impairment? Am Heart J 1995;129:11211126.

12. Marcovitz PA, Bach DS, Mathias W, Shayana V, Armstrong WF. Paradoxic hypotension during dobutamine stress echocardiography: Clinical and diagnostic implications. J Am Coll Cardiol 1993;21:1080-1086.

13. Tanimoto M, Pai RG, Jintapakorn W, Shah PM. Mechanism of hypotension during dobutamine stress echocardiography in patients with coronary artery disease. Am J Cardiol 1995;76:26-30.

14. Heinle SK, Tice FD, Kisslo J. Hypotension during stress echocardiography: is it related to dynamic intraventricular obstruction? Am Heart J 1995;130:314317.

15. Fioretti PM, Brower RW, Simoons ML, ten Kaaten H, Beelen A, Baardman T, Lubsen J, Hugenholtz PG. Relative value of clinical variables, bicycle ergometry, rest radionuclide ventriculography and 24 hour ambulatory electrocardiographic monitoring at discharge to predict 1 year survival after myocardial infarction. J Am Coll Cardiol 1986;8:40-49.

16. Villella A, Maggioni AP, Villella M, Giordano A, Turazza FM, Santoro E, Franzosi GM. Prognostic significance of maximal exercise testing after myocardial infarction treated with thrombolytic agents: the GISSI-2 database. Lancet 1995;346:523-529.

17. Reiber JHC, Serruys PW, Kooijman CJ, Wiins W, Slager CJ, Gerbrands JJ, Suurbiers JC, den Boer A, Hugenholtz PG. Assessment of short-, medium-, and long-term variations in arterial dimensions from computer-assisted quantitation of coronary cineangiograms. Circulation 1985;71:280-288.

18. Dixon WJ. BMDP Statistical Software. Berkeley, CA: University of California Press, 1992:1105-1144.

19. Pellikka PA, Roger VL, McCully RB, Mahoney DW, Bailey KR, Seward JB, Tajik JA. Normal stroke volume and cardiac output response during dobutamine stress echocardiography in subjects without left ventricular wall motion abnormalities. Am J Cardiol 1995;76:881-886.

20. Tanimoto M, Pai RG, Jintapakorn W. Normal changes in left ventricular filling and hemodynamics during dobutamine stress echocardiography. $J$ Am Soc Echocardiogr 1995;8:488-493.

21. Beleslin BD, Ostojic M, Stepanovic J, Djordjevic-Dikic A, Stojkovic S Nedeljkovic M, Stankovic G, Petrasinovic Z, Gojkovic L, Vasiljevic-Pokrajcic $\mathrm{Z}$, Nedeljkovic S. Stress echocardiography in the detection of myocardial ischemia. Head-to-head comparison of exercise, dobutamine, and dipyridamole tests. Circulation 1994;90:1168-1176.

22. Pellikka PA, Oh JK, Bailey KR, Nichols BA, Monahan KH, Tajik JA. Dynamic intraventricular obstruction during dobutamine stress echocardiography. A new observation. Circulation 1992;86:1429-1432.

23. Rosamond TL, Vacek JL, Hurwitz A, Rowland AJ, Beauchamp GD, Crouse LJ. Hypotension during dobutamine stress echocardiography: initial description and clinical relevance. Am Heart J 1992;123:403-407.

24. Weissman NJ, Nidorf SM, Weyman AE, Picard MH. Effect of hydration on cavity obliteration during dobutamine stress echocardiography. Clin Cardiol $1995 ; 18: 17-20$

25. Mark AL. The Bezold-Jarisch reflex revisited: clinical implications of in hibitory reflexes originating in the heart. J Am Coll Cardiol 1983;11:90-102. 26. Mazeika PK, Nadazdin A, Oakley CM. Clinical significance of abrupt vasodepression during dobutamine stress echocardiography. Am J Cardiol 1992;69:1484-1487.

27. Lakatta EG, Cohen JD, Fleg JL, Frohlich ED, Gradman AH. Hypertension in the elderly: age- and disease-related complications and therapeutic implications. Cardiovasc Drugs Ther 1993:7;643-653.

28. Hogue CW Jr, Dávila-Román VG, Stein PK, Feinberg M, Lappas DG, Pérez JE. Alterations in heart rate variability in patients undergoing dobutamine stress echocardiography, including patients with neurocardiogenic hypotension. Am Heart J 1995;130:1203-1209. 